\title{
Thyroid Function Abnormalities in Patients Receiving Anticancer Agents
}

\author{
Francesco Torino, Agnese Barnabei, \\ Roberto Baldelli and Marialuisa Appetecchia
}

Additional information is available at the end of the chapter

http://dx.doi.org/10.5772/50375

\section{Introduction}

Advances in systemic chemotherapy and radiotherapy have had a profound effect on the prognosis of patients affected by many cancer histotypes. Nonetheless, one of the main challenges for modern oncology is in improving the tolerability of these treatments. The frequency and pathophysiology of the most common side effects induced by cytotoxic agents are well known. They may be immediate or delayed in onset and prevalently involve bone marrow, gastrointestinal system, liver, and cutaneous annexes.

Abnormalities in thyroid function and thyroid disease are variably associated with cancer or cancer therapy [1]. These disorders encompass a broad variety of pathophysiological mechanisms, may be subtle in presentation, sometimes difficult to be identified, and even more difficult to relate to a particular chemotherapeutic regimen due to the lack of specific wide clinical trials [2]. The alteration of thyroid hormone metabolism, more commonly known as "euthyroid sick syndrome", may occur in patients with advanced cancers. Thyroid dysfunction, such as the altered synthesis or clearance of thyroid hormone-binding proteins are observed in certain malignancies, or may be caused by treatments that modify total but not free concentration of thyroid hormones. However, the clinical influence of this abnormalities is marginal, if any.

Endocrine disorders are among the most commonly reported long-term complications of cancer treatment by adult survivors of childhood cancers [3]. In adults, cytotoxic drugs are infrequently associated to overt endocrine toxicity. However, excluding gonadotoxic consequence [4], only few studies thoroughly evaluated the endocrine dysfunction induced by cytotoxic anticancer therapy in this population [2]. Similarly, hormonal therapies, widely used as effective treatment of patients affected by endocrine responsive breast cancer and 
prostate cancer, have shown only marginally influence on thyroid function and thyroid toxicities attributed to these drugs are anecdotic.

In contrast to cytotoxics and hormonal therapies, several novel antineoplastic agents, including targeted therapies and immunotherapies, are unexpectedly associated with thyroid dysfunction and thyroid disease, despite their high selectivity of action [5].

Even diagnostic procedures using iodinated contrast agents can be associated with acute effects on the thyroid, including hyperthyroidism (i.e. in patients with thyroid autonomous nodules or mild Graves disease), or transient hypothyroidism (i.e. in patients with Hashimoto thyroiditis) [6,7]. Radiation therapy can be responsible for hypothyroidism from direct damage on the thyroid or secondary to hypopituitarism from brain irradiation. Irradiation received during childhood has been associated with thyroid nodules and thyroid cancer [8].

In this chapter, available data on thyroid abnormalities induced by anticancer drugs only are discussed.

\section{Cytotoxic agents}

Cytotoxic chemotherapy seems to alter endocrine functions in a relatively small proportion of patients and is infrequently associated with thyroid abnormalities in the absence of irradiation. Cytotoxics may sensitize the thyroid gland to the effects of concomitant radiation therapy, increasing the risk of radiation-induced primary hypothyroidism [9].

In a small published series, some agents such as 5-fluorouracil, glucocorticoids, estrogens, tamoxifen, podophyllin and L-asparaginase alter levels of thyroid hormone-binding proteins without any clinical consequence [10-15]. L-asparaginase can also be responsible for transient hypothalamic or pituitary hypothyroidism [16]. Other agents such as lomustine, vincristine, and cisplatin have in vitro effects on thyroid cells, but clinically relevant consequences have not been reported [17]. Mitotane is the only active agent against advanced adrenocortical cancer (ACC) and is under evaluation in patients who underwent radical resection of this rare disease. Mitotane showed a complex interference on the endocrine system that may require multiple hormone replacement therapy. In a prospective trial [18] on 17 patients who underwent radical resection for ACC, a marked reduction in free-T4 (FT4) levels was found, without any significant changes in serum thyroid stimulating hormone (TSH) and free-T3 (FT3) concentration. FT4 reduction was inversely correlated with mitotane concentrations and dropped in the hypothyroid range in most evaluable patients. These findings mimic central hypothyroidism and are consistent with data from clinical experiments which showed that mitotane directly reduces both secretory activity and cell viability on pituitary TSH-secreting mouse cells [19]. Alternatively, it has been suggested that mitotane may affect deiodase activity, thus changing the FT4 to FT3 ratio. However, despite limited information on free thyroid hormone concentrations during mitotane treatment has been reported, for some patients thyroxine replacement may be necessary [20]. 
An increased incidence of primary hypothyroidism has been documented in patients treated with multiple drug regimens, with or without radiotherapy [2]. In patients with testicular cancer who received combinations of cisplatin, bleomycin, vinblastine, etoposide, and dactinomycin, 4 out of 27 individuals (15\%) developed primary hypothyroidism. In particular, the cumulative doses of cisplatin and vincristine seem to exacerbate these symptoms [21]. In another trial evaluating the combination of mechlorethamine, vinblastine, procarbazine and prednisolone (MOPP regimen) as treatment of Hodgkin's disease, $44 \%$ of patients developed elevated serum TSH concentrations, even though a causative role of iodine load during lymphangiograpy cannot be excluded [22]. Children with brain tumors (not involving the hypothalamic-pituitary axis) who receive vincristine, carmustine or lomustine, and procarbazine in combination and brain irradiation have a $35 \%$ incidence of hypothyroidism, compared with a $10 \%$ incidence in the group with brain irradiation alone [23]. Young age and use of chemotherapy have been associated with a higher incidence of hypothyroidism in patients receiving radiotherapy for medulloblastoma [24]. Again, the highest incidence occurred when the thyroid gland was included in the radiation field. Finally, there is no evidence that cytotoxic agents by itself may represent a risk factor for developing thyroid tumors, compared to radiotherapy [2].

\section{Immunoregulatory agents}

\subsection{Cytokines}

\subsubsection{Interferon- $\alpha$}

Interferon- $\alpha$ is a human recombinant cytokine that increases the expression of major histocompatibility complex (MHC) class I and tumor-specific antigens on the tumor cell surface, stimulating immune-mediated destruction of these cells, as well as possibly exerting direct antitumor effects [25]. Interferon- $\alpha$ demonstrated variable efficacy in patients affected by melanoma, renal cell carcinoma (RCC), AIDS-related Kaposi's sarcoma, follicular lymphoma, hairy cell leukemia, and chronic myelogenous leukemia [25]. Reduction in viral load is another relevant activity of interferons. In combination with ribavidin, interferon- $\alpha$ prolongs survival in patients with hepatitis C [26,27]. Flu-like syndrome, malaise, neuropsychiatric disorders, hematologic and liver toxicity are the most common doselimiting side-effects.

Thyroid diseases secondary to treatment with Interferon- $\alpha$ are common and may become clinically evident as destructive thyroiditis, autoimmune hypothyroidism or Graves-like hyperthyroidism. Patients receiving the drug for hepatitis appear more prone to present thyroid dysfunction than patients with malignant disease [28]. However, the infection from the hepatitis $C$ virus itself has been demonstrated to increase the risk of thyroid damage [28]. The pegylated form of interferon- $\alpha$ is more effective than interferon- $\alpha$ in triggering antiviral response, but showed a similar rate of thyroid dysfunction [29].

Destructive or autoimmune thyroiditis is the most common thyroid abnormality following treatment with interferon- $\alpha$. This condition may lead to hypothyroidism after a brief 
thyrotoxic phase and usually occurs in the first few weeks of interferon treatment and is in close temporal relationship with the appearance of thyroid autoantibodies, especially antithyroglobulin (anti-TG) antibodies. Another form of autoimmune thyroid toxicity associated to interferon- $\alpha$ is characterized by the development of thyroid antibodies without hypothyroidism. In the setting of interferon therapy, the risk of hypothyroidism is $2.4 \%-$ $10 \%$ [30-35], with a risk of thyroid autoimmunity onset (including development of thyroid autoantibodies) approaching $20 \%$ [36,37]. Hypothyroidism is persistent in the majority of patients [33,38], even though although transient hypothyroidism has also been described [39]. The presence of anti-thyroperoxidase (anti-TPO) antibodies before treatment considerably increases the risk of hypothyroidism [40-42]. Thyroid abnormalities can occur as early as 4 weeks and as late as 23 months after initiating treatment, with a median of 4 months [30,34].

Interferon- $\alpha$ has also been associated with classical Graves disease and sometimes Graves' ophthalmopathy also develops, however the latter is less common [30]. This condition does not generally remit on withdrawal of the drug [35].

Several evidence supports the hypothesis that thyroid toxicity may likely be related to an autoimmune response to interferon- $\alpha$. Overexpression of MHC class I antigens are associated with activation of cytotoxic T-cells resulting in cellular destruction [43]. It has been reported that interferon- $\alpha$ increases MHC class I expression on thyroid tissue from Graves patients, provided that lymphocytes are present in the thyroid tissue [44]. Hence, interferon- $\alpha$ might worsen local immune response in subjects who have preexisting subclinical thyroiditis with intrathyroidal lymphocytes [44]. In addition, interferon- $\alpha$ can shift the immune response to a Th1-mediated immune response, with increased production of the proinflammatory cytokines interferon- $\gamma$ and interleukin-2, which may in turn amplify an autoimmune response. Interferon- $\alpha$ has been demonstrated to elicit a direct damage on thyroid cells, which may be responsible for the onset of destructive thyroiditis [28,35,42,45]. However, despite accumulating evidence, the precise mechanisms underlying thyroid toxicity associated to interferon, especially in cancer patients, remain to be elucidated.

Levothyroxine (LT4) therapy is indicated as treatment of interferon-induced hypothyroidism and withdrawal of interferon is not generally needed. When destructive thyroiditis is present, treatment with corticosteroids is needed and $\beta$-blockers are often useful to control the signs and symptoms of thyrotoxicosis. When interferon causes hyperthyroidism, antithyroid agents such as methimazole or propylthiouracil may be administered, if clinically indicated. In patients with relapsing flares of thyroiditis during prolonged courses of interferon- $\alpha$, ablation with ${ }^{131}$ I during remission may be offered to prevent further episodes of the condition [46].

Despite specific recommendations for patients treated with interferon- $\alpha$ for oncological diseases are lacking, it appears rational to apply the recommendations available for patients with hepatitis C [47]. In particular, the same serological screening is suggested, including pretreatment TSH and anti-TPO antibodies evaluation, followed by TSH serum 
measurement every 2 months and then every six months in the case of negative anti-thyroid peroxidase (anti-TPO) antibodies [1].

\subsubsection{Interleukin-2}

Interleukin-2 is a cytokine involved in several mechanisms of immune response, including activation of natural killer cells and antigen-specific T-cells. These properties are used to stimulate tumor cell killing, also in combination with interferon or lymphokine-activated killer cells. Interleukin-2 is approved for the treatment of metastatic melanoma and RCC, although its use has been recently reduced in concomitance with the availability of more effective and better tolerated agents.

Several autoimmune side-effects have been associated to interleukin-2 therapy, including thyroid disease with an incidence of $10 \%-50 \%$ [48-54]. Hypothyroidism usually occurs $4-17$ weeks after initiation of treatment $[48,49]$. It may be reversible following discontinuation of the drug $[49,55]$. Most patients who developed hypothyroidism showed positive anti-TG or anti-TPO antibodies. In addition to hypothyroidism, thyroiditis and thyrotoxicosis have also been reported at a lesser frequency [55,56]. An early phase of presumably destructive thyrotoxicosis is common, with variable degrees of hyperthyroidism [57].

Evidence suggests that thyroid disease associated to interleukin-2 may be induced by stimulating autoreactive lymphocytes, leading to autoimmune thyroiditis. Patients under treatment with interleukin-2 showed high levels of interferon- $\gamma$ and tumor necrosis factor- $\alpha$, which may trigger autoimmunity by enhancing the presentation of human leukocyte antigen class II and associated autoantigens by thyrocytes. Also, interleukin-2 may have direct effects on thyrocyte functioning [58,59]. Increase in serum thyroid autoantibodies levels [48,53] and lymphocyte infiltration of the thyroid gland [57] were found in patients treated with interleukin-2, suggesting a cell-mediated autoimmune mechanism. Similarly to interferon, preexisting positivity of thyroid autoantibodies seems to predict an increased risk of developing hypothyroidism during interleukin-2 treatment [49].

Occurrence of hypothyroidism was associated with a favorable response to treatment $[48,60]$, but other studies did not confirm these results [61]. It has been suggested that thyroid dysfunction may develop more often in the responders because they receive longer courses of the treatment [46,62]. Patients with interleukin-2-induced hypothyroidism may be treated with LT4, while thyrotoxicosis only requires symptom control with $\beta$-blockers and corticosteroids. Measuring TSH before treatment and then every 2-3 months during treatment with interleukin-2 is advisable [1].

\subsection{Thalidomide and lenalidomide}

Thalidomide and lenalidomide are immunomodulatory drugs with antineoplastic activity $[63,64]$. These agents enhance T-cell stimulation and proliferation, induce endogenous cytokine release, and increase number and function of natural killer cells, thus enhancing 
immune-mediated destruction of tumor cells. They also inhibit proliferation and induce apoptosis of tumor cells and exert antiangiogenic activity [63,64].

Thalidomide and lenalidomide are approved for the treatment of multiple myeloma. Lenalidomide has also been approved for $5 q$ myelodysplastic syndrome. Both agents are under evaluation for the treatment of several solid tumors, including thyroid cancer [65-67] and for a range of autoimmune diseases [68].

Hypothyroidism has been associated to treatment with these drugs with varying grades and frequency [68-71]. In a recent study on patients affected by multiple myeloma and treated with thalidomide [69], subclinical hypothyroidism was reported in $20 \%$ of participants, and $7 \%$ showed overt hypothyroidism, mostly occurring 1-6 months after initiating treatment [69].

Lenalidomide is more potent and showed a more favorable toxicity profile compared to thalidomide $[72,73]$. Hypothyroidism due to lenalidomide has been reported in $5 \%-10 \%$ of patients [74,75]. Thyroid abnormalities were found in 10 out of 170 patients who received lenalidomide for various hematological cancers. After a median of 5 months of therapy the patients reported both hypothyroidism and thyrotoxicosis. However, many of them had been exposed to prior radiation or thalidomide [76].

Many mechanisms have been suggested for the hypothyroidism induced by these drugs [69], including inhibition of thyroid hormone secretion [77] or a reduction of iodine uptake into follicular cells [78]. Most probably, since thalidomide and lenalidomide exert an antiangiogenic activity, compromise the blood flow to the thyroid may explain thyroid toxicity [69]. In some patients, TSH suppression has been documented before the development of hypothyroidism, suggesting ischemic thyroiditis [69]. Alternatively, a thyrotoxicosis triggered by an immune-mediated destructive thyroiditis may be hypothesized. This condition may be induced by deregulation of cytokine levels or through direct effects on T-lymphocytes [69]. A direct toxic effect on thyroid cells is also possible, but this has not been evaluated. TSH measurement before treatment and then every $2-3$ months during treatment is recommended [1,79].

\subsection{Anti-CTLA4 monoclonal antibodies}

Ipilimumab and tremelimumab are monoclonal antibodies directed against cytotoxic Tlymphocyte-associated antigen 4 (CTLA-4) (anti-CTLA-4 mAbs), a receptor expressed on Tcells that exerts a suppressive effect on the immune response after T-cell/antigen-presenting cell interaction [80]. Blocking the receptor, an increased T-cell activation and antitumor effects are obtained. Ipilimumab is approved for the treatment of unresectable or metastatic melanoma.

These agents have been associated with several immune-related adverse events (IRAEs), most frequently enterocolitis, hepatitis, cutaneous reactions [81-83]. The spectrum of autoimmune endocrine adverse events experienced by patients treated with anti-CTLA-4 mAbs includes hypopituitarism, primary thyroid disease, and sporadically primary adrenal 
insufficiency [84]. The prevalence of autoimmune hypophysitis varies among different studies $(0 \%-17 \%)$ [85], being $3-5 \%$ in larger studies. Similarly to classical autoimmune hypophysitis, secondary hypothyroidism has been reported in patients who develop hypophysitis induced by anti-CTLA-4 monoclonal antibodies.

Direct damage to the thyroid induced by these agents presents two clinical common forms: hyperthyroidism in Graves' disease and thyroid destruction with hypothyroidism in Hashimoto's thyroiditis. Since these conditions are classically included in autoimmune thyroid diseases phenotype and previous studies suggested that CTLA-4 is a candidate gene conferring susceptibility to thyroid autoimmunity [86], an autoimmune pathogenesis has also been suggested for thyropathies induced by anti-CTLA4-mAbs (anti-CTLA4-IT). The incidence of these conditions varies from 0 to $4 \%$ among the different trials. In two studies $[87,88]$, tremelimumab (15 mg/Kg body weight) was associated with thyreopathy (hyper/hypothyroidism, autoimmune-thyroiditis, or Graves' disease) in $4 \%$ of cases. In studies on ipilimumab, the reported incidence of anti-CTLA4-IT was apparently lower, namely 0-2\%, being mild hypothyroidism the most frequent thyroid side-effect. Recently, Hodi et al. in a large phase III trial, reported for the first time an improvement in overall survival obtained by ipilimumab in pretreated patients affected by metastatic melanoma [89]. The treatment was associated with thyroid disorders or abnormal thyroid function tests in approximately $2 \%$ of patients. In a randomized phase II study on a cohort of 115 patients affected by metastatic melanoma, evaluating the potential protective effect of budesonide on IRAEs induced by ipilimumab, hypothyroidism was diagnosed in $5.3 \%$ of patients who received ipilimumab with placebo ( 3 out of 57 patients; with severe hypothyroidism in one of them, 1.8\%), compared with no cases in the group of patients treated with budesonide as well. These data suggest a potential protective effect of budesonide in terms of reduced incidence of ipilimimab-related thyroiditis, but this hypothesis needs to be confirmed in specifically designed clinical trials [90].

In a phase I study [91] evaluating the combination of ipilimumab $(10 \mathrm{mg} / \mathrm{Kg}$ every 3 weeks for 4 cycles, than every 3 months) with bevacizumab $(7.5 \mathrm{mg} / \mathrm{kg}$ - Cohort $1 ; 15 \mathrm{mg} / \mathrm{kg}$ cohort 2 every 3 weeks) in a group of 21 patients affected by unresectable stage III or stage IV melanoma, thyroiditis was diagnosed in $4(19 \%)$ patients. No cases of endocrine-IRAEs were reported in a trial on 36 patients who received both ipilimumab $(0.1-3 \mathrm{mg} / \mathrm{kg} ; 24$ patients received the higher dose) and interleukin-2 (720,000 IU/kg every 8 hours) which is not infrequently associated with autoimmune thyroiditis [92].

The onset of anti-CTLA4-IT appears rather earlier than other IRAEs, occurring after 2-4 infusions. In most cases the anti-CTLA4-ITs have a subclinical course or may be transient. Alternatively, this condition may be characterized either by hypothyroidism with increased serum TSH concentrations, normal free-T4, and presence of anti-TPO antibodies, less frequently anti-TG antibodies or evolve in permanent hypothyroidism, requiring thyroid hormone supplementation [93].

Sporadic cases of Graves' ophthalmopathy associated with ipilimumab therapy in euthyroid patients have been reported $[82,94]$. In these cases the effective treatment was to administer a high dose of glucocorticoids in the acute phase, rapidly tapered down and continue with 
hydrocortisone, if required. None of the patients affected by anti-CTLA4-IT showed concomitant hypophysitis or other IRAEs.

Patients who need to receive anti-CTLA-4 mAbs should be carefully informed on the importance of observing and early reporting signs or symptoms potentially related to IRAEs, and that these symptoms may occur weeks to months after starting treatment. In these patients, TSH, free-T4, serum electrolytes, serum glucose, and blood cell counts should be assessed before initiating treatment and before each cycle.

\subsection{Tyrosine kinase inhibitors}

Tyrosine kinase inhibitors (TKIs) have emerged as a new class of molecular targeted anticancer agents with proven efficacy in several types of carcinoma and in some hematologic cancers. At the moment, about 150 kinase-targeted drugs are in clinical development and many more are in various stages of preclinical development [95].

The registered kinase inhibitors are small molecules, that, with sporadic exceptions, exert their pharmacological action at the ATP-site of a wide variety of tyrosine kinases critical for tumor cell survival and proliferation and angiogenesis. TKIs compete with ATP for binding to the catalytic domain that act by preventing ATP binding to these targets with different selectivity, potency and pharmacokinetic properties. However, despite their inherent selectivity, the available TKIs showed a variable grade of affinity for the different tyrosine kinases, but none specific for a single kinase. In addition, interference is frequently extended to off-target intracellular processes of normal cells. As a direct consequence, TKIs may cause a number of infrequent or even new toxicities. TKI-induced endocrine side effects mainly include thyroid dysfunction and disease, but also may be responsible for gonadal and adrenal dyfunction, bone and glucose altered metabolism, impairment in linear growth and fetal development [96].

Two types of thyroid dysfunctions have been observed with TKIs [97]. The first is worsening of hypothyroidism in patients under satisfactory treatment with thyroid hormone replacement. This effect was initially noted in patients under treatment with imatinib, but also other TKIs were found responsible for increase in LT4 supplementation in hypothyroid patients [98-102]. The second type of thyroid disturbance is primary hypothyroidism in patients with previously normal thyroid function. Almost all TKIs are responsible, at a variable extent, of primary hypothyroidism, with the exception of gefitinb and erlotinib.

The mechanisms of TKI-induced thyroid dysfunction are unclear. An increase in the requirement of replacement therapy with LT4 during certain TKIs has been suggested to be dependent on possible interference of the drug at nondeiodination clearance of LT4 [98]. Several drugs (e.g. phenobarbital, phenytoin, carbamazepine, rifampicin, and nicardipine) can increase thyroid hormone clearance through the induction of hepatic microsomal enzymes, including mixed function oxygenases and uridine diphosphateglucuronosyltransferases [103]. These drugs can cause hypothyroidism in patients who 
undergo LT4 [11,104-106]. For example, imatinib is a potent competitive inhibitor of several mixed function oxygenases (CYP2C9, CYP2D6, and CYP3A4/5), and the induction of uridine diphosphate-glucuronosyl transferases has been hypothesized to be a possible mechanism of interference of imatinib on levothyroxine metabolism [98]. Alternatively, an interference of sunitinib with thyroid hormone action at the pituitary level has been suggested [122].

TKI-induced hypothyroidism (de novo primary hypothyroidism) may have several explanations. In some cases thyrotoxicosis may precede the development of hypothyroidism, suggesting a thyroiditis-induced thyrotoxicosis $[107,108,123]$. Other possible mechanisms include direct toxic effects on thyrocytes, namely the reduced synthesis of thyroid hormones related to inhibition of thyroid peroxidase activity [109], impaired iodine uptake [110], the drug induced regression of the gland vascular bed with significant capillary alteration and reduction in density [111]. However, a role for iodine uptake in TKI-hypothyroidism was not confirmed by in vitro studies [112] and antiperoxidase effect seems unable to provide an explanation for cases with initial destructive thyrotoxicosis, or with thyroid atrophy.

Induction of Hashimoto thyroiditis has also been proposed [113], although Hashimoto thyroiditis is unlikely to be the main mechanism because of the low prevalence of anti-TPO antibodies.

The most likely explanation is that the thyroid dysfunction may be related to the effects of these agents on tyrosine kinase receptors involved in vascular function, such as vascular endothelial growth factor (VEGF) receptor (VEGFR). This could cause a reduction in thyroid blood flow to this extremely vascular gland. If the blood flow decreases rapidly, an ischemic thyroiditis could result, leading to a transient period of thyrotoxicosis. If the decreased blood flow develops more slowly, gradual thyroid destruction may occur with resulting hypothyroidism [114]. Supporting evidence for this theory include findings that thyroid cells express VEGF and VEGFR mRNA, and preclinical studies in mouse models have shown glandular capillary regression with TKI exposure [115]. In humans, case reports demonstrated reduced thyroid volume and reduced vascularity by Doppler ultrasound [116,117], with rapid increase in the size of the thyroid with cessation of sunitinib. This reduced thyroid volume secondary to reduced blood flow, may also explain the impaired radioactive iodine uptake in vivo, but not in vitro [118]. However, the role of VEGF in thyroid signaling is uncertain. Unlike treatment with antiangiogenic TKIs, bevacizumab is not associated with altered thyroid homeostasis [119]. In addition, in vitro experiments showed that VEGF reduces TSH induced iodine uptake by thyroid cells, and inhibition of VEGF restores iodine uptake [120]. Other factors, such as platelet derived growth factor $\alpha$ and cKIT, contribute to maintaining thyroid homeostasis, but so far no data on their role in this toxicity have been published.

\subsubsection{Imatinib}

Imatinib inhibits the kinase activity of the tyrosine kinases of breakpoint cluster region proto-oncogene ABL1 (BCR-ABL fusion protein), c-Kit and platelet derived growth factor 
receptor (PDGFR) $\alpha / \beta$. It is currently approved for the treatment of chronic myeloid leukemia, gastrointestinal stromal tumors (GIST) and dermatofibrosarcoma protuberans. The influence of daily 400-800 mg imatinib on LT4 was reported in a cohort of 11 patients (10 with medullary thyroid carcinoma and 1 with GIST) [98]. Among the patients with medullary thyroid carcinoma, eight underwent thyroidectomy and received LT4 and three had thyroid carcinoma in situ. Thyroid function was evaluated before, during and 2 weeks after therapy with imatinib or LT4. Symptoms of hypothyroidism occurred in all patients who had undergone thyroidectomy, but not in those with intact thyroid. Patients who had undergone thyroidectomy had markedly elevated TSH levels, and required an increase of LT4 during imatinib dosing. The effect was reversible after discontinuation of treatment, suggesting that imatinib might be the causative agent.

In another study on 68 patients with intact thyroid gland who received imatinib for chronic myeloid leukemia, no case of drug-induced alterations in thyroid laboratory parameters was observed. These data sustain the hypothesis that imatinib-induced thyroid dysfunction is limited to athyreotic patients and are not the consequence of a direct action of the drug on thyroid gland [121], but more probably of an interference of the drug in the nondeiodination clearance of LT4 through the induction of hepatic microsomal enzymes [98].

\subsubsection{Sunitinib}

Sunitinib is an oral, multitarget inhibitor of VEGF receptor 1 (VEGFR1), VEGFR2, Fms-like tyrosine kinase 3 (Flt3), colony stimulating factor 1 receptor (CSF1R), RET, c-Kit, and PDGFR. This agent has been found to influence the thyroid function of patients with GIST or RCC.

In total, 2 out of 56 patients with RCC and a history of well controlled hypothyroidism, and 7 out of 21 patients with imatinib-resistant GIST, had a worsening hypothyroidism during sunitinib treatment $[109,111,122]$, reported the case of a woman with GIST who was resistant to imatinib and received LT4 after thyroidectomy and ${ }^{131} \mathrm{I}$-ablation for follicular thyroid carcinoma. The patient's dose of LT4 needed to be increased after sunitinib treatment. In this report, the marked increase in TSH levels has been attributed to a potential interference of sunitinib with thyroid hormone action at the pituitary level [122].

Desai et al. [123] prospectively evaluated the thyroid function tests (TFTs) in a phase I/II study of sunitinib therapy in 42 patients with imatinib-resistant GIST. Most patients received $50 \mathrm{mg}$ sunitinib daily every $4-6$ weeks, each consisting of 2-4 weeks of sunitinib followed by 2 weeks of wash-out. Initially, TFT were performed only if clinically indicated. Thereafter, serum TSH was evaluated before each sunitinib cycle. In total, 42 patients with normal baseline TFT who received at least 3 sunitinib treatment cycles for a median of 37 weeks were evaluated. Abnormal serum TSH concentrations were documented in 26 patients (62\%). Sunitinib caused persistent primary hypothyroidism in 15 patients $(36 \%)$, after an average of 50 weeks of therapy (range 12-94 weeks). Seven additional patients $(17 \%)$ experienced transient, mild serum TSH elevation $(5.0-7.0 \mathrm{mU} / \mathrm{L})$. In 4 patients TSH was suppressed, but they discontinued treatment before the TFTs could be repeated. Out of 
15 patients with hypothyroidism, 6 (40\%) had at least one TSH value below $0.5 \mathrm{mU} / \mathrm{L}$ before developing the condition, which suggests a thyroiditis-induced thyrotoxicosis. The risk of hypothyroidism increased with the duration of sunitinib therapy. Subclinical or overt hypothyroidism was observed in 4 out of 22 patients [18\%] who received sunitinib for 9 months, and in 5 of 17 patients (29\%) who received sunitinib for longer than 12 months. In patients treated for longer than 96 weeks, $90 \%$ developed increased levels of TSH. The mean time to onset of hypothyroidism was 50 weeks. Among the patients with TSH concentrations greater than $10 \mathrm{mU} / \mathrm{L}$, none had spontaneous biochemical resolution. During the titration of LT4, serum TSH values remained elevated for a median of 17 weeks (range 4-117 weeks). The TSH concentrations returned to normal in all patients who received conventional doses of LT4. Interestingly, in 2 patients with hypothyroidism and normal baseline TFTs, ultrasonography revealed atrophic thyroid tissue, which suggests destructive thyroiditis. This clinical trial was the first to report the prevalence of sunitinib related hypothyroidism [123].

Rini et al. [111] described thyroid abnormalities in a retrospective study of 66 patients with metastatic RCC treated with sunitinib. In all, 30 patients were pretreated with cytokinebased therapy ( 6 of them were treated with bevacizumab), and 30 patients were treatmentnaive. All patients received the standard sunitinib dose of $50 \mathrm{mg}$ daily for 4 weeks, followed by 2 weeks off therapy. TFT assessment, including free thyroxine index, was initiated in 29 patients (and subsequently in another 37 patients) as a routine laboratory assessment at baseline and on day 28 of every even numbered cycle. Out of the 66 patients, 56 (85\%) had one or more TFT abnormality. These abnormalities were consistent with hypothyroidism in all patients and primarily included the elevation of TSH, decreased levels of T3 and, less commonly, decreases in T4 and/or of the free thyroxine index. TFT abnormalities were detected early (the median time of detection was at cycle 2). Among patients with abnormal TFTs, signs and symptoms related to hypothyroidism were found in 47 patients $(84 \%)$. These symptoms included fatigue, cold intolerance, anorexia, periorbital edema, fluid retention, and alterations in skin or hair. LT4 therapy was given at the discretion of the physician, on the basis of the degree of biochemical abnormality and/or clinical symptoms. A resolution of biochemical abnormalities occurred in all 17 patients treated with LT4, and an improvement of symptoms was recorded in 9 patients. Anti-TG antibodies were measured in 44 patients and were abnormal in 13 (30\%). No association was observed between the presence of anti-TG antibodies and the incidence or severity of TFT abnormalities [111].

Feldman et al. [124] reported that hypothyroidism was found in 14 (18\%) out of the 80 patients enrolled in a prospective clinical trial that investigated the efficacy of sunitinib in metastatic RCC. Serum TSH levels were obtained only from symptomatic patients and ranged from 6.0 to $146.4 \mathrm{mU} / \mathrm{L}$ (normal range $0.35-5.5 \mathrm{mU} / \mathrm{L}$ ). Hypothyroidism was detected after a median time of 10 months of therapy (range 1-26 months), being fatigue the predominant symptom. The Authors highlighted that the lower incidence of hypothyroidism reported might depend on the fact that TFT assessment was performed on symptomatic patients only [124]. 
Wong et al. [109] explored the potential effects of sunitinib on thyroid function in a cohort of 40 patients affected by different tumor histotypes, the majority of whom were affected by imatinib-resistant GIST. In this study a new onset or worsening condition of hypothyroidism occurred in 21 out of 40 patients (53\%) patients who underwent TFTs. Patients developed elevated TSH levels after a median of 5 months of treatment (range, 1-36 months). The median TSH level was $21.4 \mathrm{mU} / \mathrm{L}$ (range, $4.6-174 \mathrm{mU} / \mathrm{L}$ ). The influence of sunitinib on peroxidase activity was assessed by testing its effects on guaiacol oxidation and protein iodination caused by lactoperoxidase. The potency of sunitinib antiperoxidase activity was about $25 \%$ of that noted with propylthiouracil. The Authors proposed that the antithyroid effect of sunitinib is mediated by the inhibition of peroxidase activity, which is involved in the synthesis of the thyroid hormone [109].

Wolter et al. [125] prospectively evaluated the incidence of hypothyroidism in patients with GIST or metastatic RCC treated with sunitinib at the standard dose [125]. TFTs included assessment of serum TSH, T3, free thyroxine index and thyroid antibodies (anti-TG, antiTPO antibodies, and TSH receptor antibodies) and was measured on days 1 and 28 of each treatment cycle. The analysis revealed that 16 patients $(27 \%)$ developed sub- or clinical hypothyroidism requiring thyroid hormone replacement and 20 patients $(34 \%)$ showed at least one thyroid test abnormality. The median time to develop thyroid dysfunction was 4 weeks and patients who did not develop hypothyroidism within the first cycles did not develop hypothyroidism later during therapy.

In another prospective phase I-II study, Mannavola et al. [110] evaluated TFT (serum TSH, free T3 and T4, thyroglobulin, anti-TG and anti-TPO antibodies) in 24 patients with GIST who were treated with sunitinib (4 weeks of $50 \mathrm{mg}$ daily and 2 weeks of withdrawal). Urinary iodine was measured in 18 patients and urinary fluorine was assessed in 10 patients. Thyroid ultrasonography and echocolor-Doppler were performed, both at enrollment and after a variable number of treatment cycles. To study thyroid function, ${ }^{123}$ I thyroidal uptake and scintigraphy were performed in 6 unselected patients at the end of the treatment and withdrawal periods. Hypothyroidism was documented in $46 \%$ of patients, and a transient elevation of TSH levels in $25 \%$ of cases. The overall prevalence of elevated TSH levels after sunitinib was $71 \%$. At onset, hypothyroidism was subclinical in all but one patient with Hashimoto thyroiditis, the only one with detectable antithyroid autoantibodies. TSH levels were found to fluctuate according to whether treatment was given or withdrawn, and progressively increased during treatment. In most cases, progressive worsening of hypothyroidism was shown, but in a few cases a sudden development of severe hypothyroidism was observed. The normal echographic and echocolor-Doppler patterns, obtained both at baseline and during treatment, indicate that hypothyroidism is unlikely to be the consequence of a direct toxic effect on thyroid cells or secondary to an autoimmune process. Inhibition of iodine uptake seems to be a more likely explanation for hypothyroidism. Indeed, radioiodine uptake impairment has been demonstrated by a reduced uptake at the end of treatment periods, with a partial or total recovery during the withdrawal phase. Of particular interest was the observation of a blunted early ${ }^{123}$ I uptake curve, which suggests an alteration in the uptake phase rather than in the organification 
process. The Authors noted that after sunitinib withdrawal, TSH levels returned to the normal range in a maximum of 60 days.

Interestingly, the association between TKI-induced thyroid dysfunction and clinical efficacy has been demonstrated in two larger studies. Schmidinger et al. [126] in a prospective analysis of 87 patients with metastatic RCC who were to receive treatment with sunitinib or sorafenib, thyroid function was monitored every 4 weeks during the first 2 months of treatment and every 2 to 4 weeks thereafter. Subclinical hypothyroidism was present in five patients at baseline and was diagnosed in 30 patients (36.1\%) within the first 2 months of therapy. Patients with subclinical hypothyroidism had a statistically significant objective remission rate of $28.3 \%$ versus $3.3 \%$ in euthyroid patients $(p<0.001)$ and median duration of survival (not reached versus 13.9 months in euthyroid patients; $\mathrm{p}=0.016$ ). In addition, in a multivariate analysis, the development of subclinical hypothyroidism within 2 months of treatment was found to be an independent predictor of survival $(\mathrm{p}=0.014)$. In another study on patients with metastatic RCC who received sunitinib or sorafenib, Riesenbeck et al. [127] found that 21 (38.1\%) out of the 66 evaluable patients developed hypothyroidism. Hypothyroidism was associated with a longer PFS $(16.0 \pm 0.8$ months versus $6.0 \pm 0.8$ months, $\mathrm{p}=0.032)$. In agreement with the study by Schmidinger et al. [126], hypothyroidism was found to be an independent predictor of survival $(\mathrm{p}=0.01)$ in a multivariate analysis.

\subsubsection{Sorafenib}

Sorafenib is an oral multikinase inhibitor that inhibits the kinase activity of RAF/MEK/ERK, VEGFR2 and VEGFR3, Flt3, fibroblast growth factor receptor 1, RET, cMET, PDGFR $\beta$, Kit and other receptors involved in tumor progression and angiogenesis. It is approved for the treatment of advanced RCC and unresectable hepatocellular carcinoma. In addition, it is under clinical evaluation in a number of tumor types, including lung, pancreatic, prostate, melanoma and differentiated thyroid cancer. Tamaskar et al. [114] retrospectively investigated the incidence of TFT abnormalities in 39 patients with metastatic RCC treated with $400 \mathrm{mg}$ sorafenib twice daily. Most patients had received at least one prior treatment. Out of the 39 patients, 16 (41\%) had one or more serum TFT values outside the laboratory normal reference range during treatment with sorafenib. The median timing of the abnormal test was 1.8 months (range 0.6-7.3 months). Biochemical hypothyroidism occurred in 7 out of 39 patients $(18 \%)$ during treatment, which was first observed $2-4$ months after sorafenib initiation. Six of these patients had mild TSH level elevations (5.5-10.0 mU/L). Another patient showed a rapid onset of hypothyroidism with TSH level rising from 5.74 to $160.64 \mathrm{mU} / \mathrm{L}$, and T3 level decreasing from 72 to $49 \mathrm{ng} / \mathrm{dl}$ over 1.5 months. One patient had normal TSH concentration $(2.42 \mathrm{mU} / \mathrm{L})$ but low T3 and T4 at 4 months after starting sorafenib treatment, these abnormalities worsened over the next 4 months with further reductions of T3 and T4 levels, and abnormal TSH $(9.930 \mathrm{mU} / \mathrm{L})$. Both these patients received LT4. In two of the seven hypothyroid patients anti-TG antibody titers increased; two patients had persistent serum TSH elevation and in one case a normalization of the TSH values was observed. 
Clement et al. [128] prospectively monitored thyroid function in 38 patients with metastatic RCC who were treated with sorafenib $400 \mathrm{mg}$ twice daily. Thyroid function was assessed at baseline and on day 1 of each treatment cycle. Out of 23 patients with normal baseline thyroid function, seven patients $(30 \%)$ developed at least one elevated serum TSH and 1 patient $(5 \%)$ developed low TSH levels. For these abnormalities no therapy was required. In addition, out of 15 patients with either thyroid dysfunction at baseline or previous treatment potentially interfering with thyroid function, two patients with baseline subclinical hypothyroidism (defined as an increase in serum TSH above normal and $\leq 10 \mathrm{mU} / \mathrm{L}$, with normal T3 and T4 values) developed clinical hypothyroidism (TSH $\geq 10 \mathrm{mU} / \mathrm{L}$ or T3 and T4 values below the normal range) requiring thyroid hormone replacement therapy.

In another prospective observational study [129] on 69 Japanese patients affected by metastatic RCC refractory to cytokine therapy and subsequently treated with sorafenib for at least 12 weeks, thyroid function was assessed before and every 4 weeks after the initiation of sorafenib treatment. Forty-six (67.7\%) patients developed hypothyroidism. Interestingly, $11(23.9 \%)$ of these patients first showed a suppressed TSH value accompanying the increase in free T3 and/or free T4, before developing hypothyroidism. This pattern clearly suggests that sorafenib may have induced thyroiditis. LT4 was needed by 4 patients $(5.8 \%)$ who presented severe clinical symptoms caused by hypothyroidism. Among several factors examined, only age was significantly associated with the risk of developing hypothyroidism.

Sorafenib-associated thyroid dysfunction was not reported in two registration trials in patients affected by advanced hepatocellular carcinoma (HCC). More recently, in a series of 38 consecutive patients with HCC treated with sorafenib, $5(13 \%)$ of them developed subclinical hypothyroidism (TSH levels, 7,41 $\mu \mathrm{IU} / \mathrm{mL}$; range, 6,38-8,94 $\mu \mathrm{IU} / \mathrm{mL}$ (unpublished data) [130]. Other case reports of patients affected by HCC showed progressive destructive thyroiditis after taking sorafenib. These data highlight the possibility that also hypothyroidism induced by sorafenib may be the result of an initial thyrotoxicosis [131].

Abdulrahman et al. [132] in a small prospective study on 21 patients with progressive nonmedullary thyroid carcinoma treated with sorafenib, measured serum total T4, free T4, total T3, free T3, reverse T3, and TSH concentrations at baseline and after 26 weeks of treatment with sorafenib. Results from this study suggested that sorafenib enhances T4 and T3 metabolism, which may be probably caused by an increased type 3 deiodination.

\subsubsection{Motesanib}

Motesanib diphosphate is a highly selective, oral inhibitor of VEGFR-1, -2, and -3; PDGFRs and c-KIT. The association between motesanib and thyroid function was recognized in a phase II study of 93 patients with progressive radioiodine-resistant differentiated thyroid cancer who daily received motesanib diphosphate [102]. All the patients had previously undergone thyroidectomies and were on thyroid hormone replacement therapy. Increased serum TSH concentrations, hypothyroidism or both were observed in 20 patients $(22 \%)$. The Authors suggested that alterations in the absorption or metabolism of LT4 may explain changes in thyroid hormone levels while on motesanib. 
In a phase II study [101] on 91 patients affected by locally advanced or metastatic medullary thyroid cancer (MTC), motesanib was taken orally at the standard dose for up to 48 weeks or until unacceptable toxicity or disease progression. Thirty-seven patients $(41 \%)$ had elevated serum TSH levels compared with baseline and/or hypothyroidism.

In another phase II study assessing the tolerability and activity of motesanib in 138 patients with imatinib-resistant GIST, only 3 patients ( $2 \%$ ) developed hypothyroidism, but only in one case related to treatment [133].

\subsubsection{Vandetanib}

Vandetanib is an oral inhibitor of VEGFR-2 and -3, RET kinases, and at higher concentrations, the epidermal growth factor receptor kinases. This drug has been approved in the United States for unresectable locally advanced or metastatic MTC and is under evaluation in phase III trials on patients affected by several cancer types [134].

In a phase II study of vandetanib, 19 patients with advanced hereditary MTC received vandetanib $100 \mathrm{mg}$ daily [135]. All patients had undergone prior total thyroidectomy and were receiving LT4 therapy. In all 17 patients who had available baseline TFTs, an increase in serum TSH levels was observed. TSH elevation reached a maximum by day 84 after the start of vandetanib treatment with a median 7.3-fold increases over baseline. No patients were reported to have symptomatic hypothyroidism, but LT4 was increased in two patients.

Interestingly, in a study on 39 patients with progressive medullary or differentiated thyroid cancer included in two randomized placebo-controlled trials using vandetanib $300 \mathrm{mg} /$ day [136] LT4 had to be increased by $50 \mu \mathrm{g} / \mathrm{d}$ to maintain serum TSH within the normal range, probably by increased type 3 deiodinase activity as described using sorafenib [132].

\subsubsection{Axitinib}

Axitinib is an oral TKI that acts selectively inhibiting all VEGFR kinases [137]. The drug is approved by the FDA for the treatment of advanced RCC after the failure of one prior systemic therapy. In a Japanese study on 18 patients affected by various solid tumors receiving axitinib at different dosage, $16(89 \%)$ patients experienced elevation in serum TSH above the upper limit of normal range [138].

In a phase II study on 60 patients with thyroid cancers resistant or not appropriate for ${ }^{131}$, who received axitinib (starting dose, $5 \mathrm{mg}$ orally twice daily), no thyroid tests abnormalities were registered, except for the initial decreases in thyroglobulin seen in most patients, regardless of their clinical response to therapy. In another phase II study on 62 patients with metastatic RCC refractory to prior therapies, including sorafenib, G1-2 hypothyroidism was registered in $29 \%$ of patients [139]. In preclinical studies with axitinib inhibition of VEGFR-2 and VEGFR-3 induced by axitinib lead to thyroid capillary regression [115,140]. Again, destructive thyroiditis mediated by the destruction of thyroid capillary appears a plausible mechanism of action explaining axitinib-associated hypothyroidism. 


\subsubsection{Nilotinib}

Nilotinib is a second-generation TKI with greater potency and specificity for BCR-ABL inhibition compared with imatinib [141,142]. It is approved for the treatment of Philadelphia-positive chronic myeloid leukemia (Ph-positive CML). Kim et al. [143] retrospectively assessed the effect of nilotinib on TFT in 55 patients with Ph-positive CML. In 12 patients (22\%), TFTs were consistent with hypothyroidism (6 subclinical, 6 clinical) and in 18 (33\%) patients with hyperthyroidism (10 subclinical, 8 clinical) at some point during their therapy. Six (11\%) of these patients were on thyroid medication prior to starting the nilotinib and in most patients an increase in LT4 dose was not required. In 4 patients evidence of thyroiditis was found ( 3 had positive anti-thyroid antibodies) with an episode of hyperthyroidism preceding the development of hypothyroidism.

Recently, a case of overt hypothyroidism following initiation of treatment with nilotinib has been described in a 76-year-old euthyroid male with CML [144]. Serum TSH was 30.23 $\mu \mathrm{U} / \mathrm{mL}$ with low free $\mathrm{T} 4$ and free $\mathrm{T} 3$, and negative anti-thyroid antibodies. The ultrasound examination showed a normal size gland, markedly decreased inhomogeneous echo signals and slightly reduced vascularity, all compatible with thyroiditis. In this case symptoms dramatically regressed following the initiation of LT4 and nilotinib was not withdrawn.

\subsubsection{Dasatinib}

Dasatinib is another second-generation TKI with activity against BCR-ABL and Src family kinases that is approved for the treatment of imatinib-resistant Ph-positive CML and Phpositive acute lymphoblastic leukemia [145]. In a retrospective survey on patients with $\mathrm{Ph}$ positive CML who received dasatinib, 5 (50\%) patients had TFT abnormalities consistent with hypothyroidism (4 subclinical, 1 clinical) and 2 patients $(20 \%)$ had thyroid values consistent with subclinical hyperthyroidism. No patient required LT4, except one patient who developed hypothyroidism and was also taking amiodarone, a medication known to cause thyroid dysfunction. Two patients were on LT4 prior to starting dasatinib and modification of LT4 was not required [143].

\subsubsection{Pazopanib}

Pazopanib is an oral angiogenesis inhibitor targeting VEGFR-1, PDGFR, and c-Kit. Pazopanib is under clinical development for the treatment of multiple tumor types and has been recently approved for the treatment of advanced RCC. Preliminary data on the incidence and severity of thyroid dysfunction in patients who received pazopanib as treatment for RCC in 3 prospective trials have been recently reported [146]. TFTs were systematically assessed in 578 patients with serum TSH values collected at baseline and every 12 weeks and serum free T3 and T4 at baseline and if TSH was abnormal during the treatment. Elevated TSH $(>5 \mu \mathrm{UI} / \mathrm{mL})$ before initiating pazopanib was found in $37(6 \%)$ patients. TSH value $>5 \mu \mathrm{UI} / \mathrm{mL}$ during the treatment was found in $167(29 \%)$ patients. Overt hypothyroidism was diagnosed in $34(6 \%)$ patients. Hyperthyroidism was seen in $8(1 \%)$ 
patients. Only 20 (3\%) patients with a TSH elevation received LT4. Hypothyroidism was registered as a Grade 1/2 adverse event in $26(4 \%)$ patients. Thyroid dysfunction was never reported as a severe adverse event in any patient.

\subsubsection{Cediranib}

Hypothyroidism was also reported with cediranib, another blocker of VEGFR 1-3 and c-Kit kinases in $45 \%$ of patients affected by advanced non-small-cell lung cancer enrolled in a randomized, double-blind trial of carboplatin and paclitaxel taking either oral cediranib or placebo daily [147]. Similarly, in a randomized phase II study on 46 patients affected by recurrent epithelial ovarian or fallopian tube cancer and treated with cediranib as single agent, Grade 2 hypothyroidism occurred in $56 \%$ of patients [148]. Details regarding the rate of patients requiring LT4 or effects of this treatment on hypothyroidism-related symptoms was not reported.

\subsection{Bexarotene}

Bexarotene is a selective agonist of the retinoid $X$ receptor (RXR), a nuclear hormone receptor. It is approved for the treatment of cutaneous $\mathrm{T}$ cell lymphoma and has been found to induce secondary hypothyroidism [102]. Bexarotene appears to interfere with the normal feedback of thyroid hormone on the pituitary gland [102,149]. T3 binding to its receptor in the pituitary leads to heterodimerization of the receptor with RXR, which suppresses transcription of the $\beta$-subunit of TSH, which is required for thyroid stimulation. Bexarotene also has TSH-independent effects on thyroid hormone metabolism. Thyroidectomized thyroid cancer patients receiving thyroid hormone replacement who started bexarotene had a dramatic decrease in total T3 and T4, and free T4 levels with TSH levels that failed to rise appropriately [150].This may be probably due to an effect on peripheral thyroid hormone metabolism via non-deiodinase mechanisms.

\section{Why is it important to assess thyroid function in cancer patients?}

Abnormalities of thyroid function induced by anticancer drugs are variably common, accordingly to the agent used. Identifying thyroid dysfunction and disease in cancer patients may have important consequences for diagnostic, therapeutic and prognostic purpose.

Diagnostic challenges are tendered by symptoms of thyroid dysfunction. For example, fatigue and constipation are present in the majority of patients with hypothyroidism, but they may be caused also by underlying malignancy, antineoplastic treatment(s) received, or medications used for control of other symptoms (i.e. nausea or pain) [1]. Similarly, many symptoms of thyrotoxicosis are similar to those attributable to other complications, such as sepsis. Inability to diagnose the presence of thyroid dysfunction or disease as treatmentrelated toxic effects may lead to misguided treatment strategies, unjustified dose reduction or even to treatment withdrawal [1]. In addition, unrecognized hypothyroidism or 
thyrotoxicosis may affect the metabolism of other medications [151]. Finally, it should be considered that thyroid dysfunction, although rarely, can lead to life-threatening consequences in cancer patients, as warned by case reports of patients who experienced myxedematous coma [152] or impaired cardiac function [153,154] as a complication of TKIinduced hypothyroidism (i.e. sunitinib).

Therefore, clinicians should maintain an adequate level of surveillance for thyroid abnormalities when patients receive certain anticancer treatments, such as TKI or certain immunomodulatory drugs, present with symptoms consistent with hypothyroidism (i.e. constipation, bradycardia, hypothermia, unexpected weight gain, dry skin or dry hair and brittle nails) or thyrotoxicosis (i.e. palpitations, weight loss, heat intolerance, frequent bowel movements, tremor, proximal muscle weakness, tachycardia, lid retraction or lid lag, insomnia, irritability, fever). Of note, hypophysitis has recently emerged as an unusual, peculiar side effect of ipilimumab/tremelimumab. Symptoms like headache, visual impairment, nausea, vomiting, loss of appetite, fatigue, weakness, asthenia, fever, lethargy, hypotension, hypoglycemia and hyponatremia in patients recently treated with ipilimumab should lead physicians to suspect hypophysitis. The early diagnosis of this side-effect allows to prevent primarily a life-threatening complication such as adrenal insufficiency, but also central hypothyroidism and other endocrine consequences of hypopituitarism [84]. Monitoring thyroid function even in asymptomatic patients has emerged as a prognostic tool as well. A lower cancer risk and a more indolent disease has been noted in patients with primary hypothyroidism and breast cancer [155]. The association between the appearance of treatment-induced hypothyroidism has been related to an increased likelihood of response to therapy and even of better outcomes. The development of hypothyroidism following radiotherapy for head and neck cancer was associated with better survival [156]. Propylthiouracil-induced hypothyroidism was associated with improved survival in patients with glioma [157]. Thyroid autoimmunity may predict an improved tumor response to interleukin 2 therapy for melanoma [62] and RCC [48,49,60]. When patients with RCC are treated with sorafenib or sunitinib, a higher rate of remission and better overall survival are seen in those who developed hypothyroidism compared to those who did not $[126,158]$. Studies of anti-CTLA4 monoclonal antibodies suggest that the presence of immune-related adverse events, including hypophysitis and thyroiditis, is associated with better clinical outcomes [159].

In patients who are going to start drugs potentially associated with thyroid side-effects, an accurate screening for thyroid function should be carried out at baseline and monitored throughout the period of treatment and follow-up. Despite specific guidelines generated by high level evidence are lacking, rational approaches have been proposed $[1,160]$.

Successful treatment of thyroid dysfunction such as hypo- and hyperthyroidism, is likely to improve patient quality of life and may prevent erroneous withdrawal from effective anticancer therapies. Patients with TSH greater than $10 \mathrm{mIU} / \mathrm{L}$ or with low free T4 levels, should receive thyroid hormone replacement with LT4 at an average dose of $1.6 \mu \mathrm{g} / \mathrm{kg}$ per day. In the case of coronary artery disease, a lower initial dose (e.g. $50 \mu \mathrm{g} / \mathrm{d}$ ) should be used 
for the first few weeks [1]. Monitoring thyroid hormone replacement is usually carried out by serum TSH measurements, aimed at maintaining TSH within the normal range. On the contrary, in patients who develop central hypothyroidism (i.e. secondary to bexarotene and anti-CTLA4 monoclonal antibodies), TSH concentrations cannot be used, and free T4 levels should be monitored, with a goal of about $1-1.5 \mathrm{ng} / \mathrm{dL}$ [1].

The treatment of subclinical hypothyroidism (TSH $5-10 \mathrm{mIU} / \mathrm{L}$ with a normal free T4) is questionable in cancer patients. In general, treatment of this condition is discouraged in a healthy population because there is insufficient evidence of benefit $[161,162]$. However, it may be offered to patients with subclinical hypothyroidism and antiTPO/anti-TG antibodies, hypercolesterolemia, thyroid nodules, or symptoms (i.e. fatigue) that may greatly worsen quality of life of patients [5]. In one study [111], at least half of patients who started LT4 for sunitinib-associated hypothyroidism had improvement of their symptoms of fatigue [111]. Conversely, Garfield et al. [163] warned that some preclinical, epidemiological and clinical evidence suggests that LT4 is permissive for tumor growth. Possible actions of thyroid hormones on cancer cells include the amplification of EGFR, phosphorylation of insulin-like growth factor 1 receptor, stimulation of migration, a direct trophic effect on tumor cells, cell specific anti apoptotic activity and angiogenesis [164].

Practical suggestions for the treatment of individual cancer patients showing TKI-induced subclinical hypothyroidism are available [5]. However, the best approach seems to to start low-dose LT4 in individual patients as a therapeutic trial [1]. This prudent method may be extended to patients who develop this condition as a side effect of other anticancer agents. However, specific prospective studies evaluating the influence of thyroid replacement therapy in cancer patients, not only in term of quality of life, but also in term of survival, are urgently needed [165]. Thyrotoxicosis induced by anticancer drugs may result from an Hashi-toxocosis or Graves' disease. Thyrotoxicosis from thyroiditis is generally self-limiting and specific treatment is not required. Corticosteroid and $\beta$-blockers, usually propranolol, can be efficacious in symptom control. However, patients with this side effect should be monitored for subsequent hypothyroidism. Patients presenting with Graves disease, are usually treated with antithyroid drugs (i.e. methimazole), followed by ${ }^{131} \mathrm{I}$ ablation if indicated. However, due to its complexity, anticancer drug-induced thyrotoxicosis is advisable to be managed under close consultation with an endocrinologist [1].

\section{Conclusions}

Thyroid dysfunctions are emerging as a variably common endocrine toxicity of several highly selective anticancer drugs. Routine testing for thyroid abnormalities in patients receiving these agents are recommended at baseline, during the treatment and follow up. Furthermore, thyroid function tests should be included in routine toxicity assessment of TKIs and possibly in other classes of targeted drugs under clinical evaluation. Hypothyroidism per se is not an indication for dose reduction or discontinuation of these agents. The clinical relevance of overt and subclinical hypothyroidism, the value of thyroid hormone replacement in individuals with abnormal serum TSH levels following anticancer 
systemic therapy, and the correct timing of thyroid replacement therapy need to be more accurately defined. Additional prospective clinical trials are necessary to investigate these important aspects. In parallel, these trials could offer the unique opportunity to clarify the molecular mechanisms underlying thyroid toxicities induced by an increasing number of anticancer agents.

\section{Author details}

\section{Francesco Torino}

Department of Internal Medicine, Chair of Medical Oncology, University of Rome "Tor Vergata", Rome, Italy

Agnese Barnabei, Roberto Baldelli and Marialuisa Appetecchia*

Endocrinology Unit, National Institute of Cancer "Regina Elena", Rome, Italy

\section{References}

[1] Hamnvik OP, Larsen PR, Marqusee E. Thyroid dysfunction from antineoplastic agents. J Natl Cancer Inst 2011;103(21):1572-87.

[2] Yeung SC, Chiu AC, Vassilopoulou-Sellin R, Gagel RF. The endocrine effects of nonhormonal antineoplastic therapy. Endocr Rev 1998;19(2):144-172.

[3] Stava CJ, Jimenez C, Vassilopoulou-Sellin R. Endocrine sequelae of cancer and cancer treatments. J Cancer Surviv 2007;1(4):261-274.

[4] Torino F, Barnabei A, De Vecchis L, Appetecchia M, Strigari L, Corsello SM. Recognizing menopause in women with amenorrhea induced by cytotoxic chemotherapy for endocrine-responsive early breast cancer. Endocr Relat Cancer 2012;19(2):R21-33.

[5] Torino F, Corsello SM, Longo R, Barnabei A, Gasparini G. Hypothyroidism related to tyrosine kinase inhibitors: an emerging toxic effect of targeted therapy. Nat Rev Clin Oncol 2009;6(4):219-228.

[6] van der Molen AJ, Thomsen HS, Morcos SK. Effect of iodinated contrast media on thyroid function in adults. Eur Radiol 2004;14(5):902-907.

[7] Markou K, Georgopoulos N, Kyriazopoulou V, Vagenakis AG. Iodine-induced hypothyroidism. Thyroid 2001;11(5):501-510.

[8] Schneider AB, Sarne DH. Long-term risks for thyroid cancer and other neoplasms after exposure to radiation. Nat Clin Pract Endocrinol Metab 2005;1(2):82-91.

[9] Hancock SL, Cox RS, McDougall IR. Thyroid diseases after treatment of Hodgkin's disease. N Engl J Med 1991;325(9):599-605.

[10] Beex L, Ross A, Smals A, Kloppenborg P. 5-fluorouracil-induced increase of total serum thyroxine and triiodothyronine. Cancer Treat Rep 1977;61(7):1291-1295.

[11] Surks MI, Sievert R. Drugs and thyroid function. N Engl J Med 1995;333(25):1688-1694.

\footnotetext{
${ }^{*}$ Corresponding Author
} 
[12] Dong BJ. How medications affect thyroid function. West J Med 2000;172(2):102-106.

[13] Mamby CC, Love RR, Lee KE. Thyroid function test changes with adjuvant tamoxifen therapy in postmenopausal women with breast cancer. J Clin Oncol 1995;13(4):854-857.

[14] Garnick MB, Larsen PR. Acute deficiency of thyroxine-binding globulin during Lasparaginase therapy. N Engl J Med 1979;301(5):252-253.

[15] Ferster A, Glinoer D, Van Vliet G, Otten J. Thyroid function during L-asparaginase therapy in children with acute lymphoblastic leukemia: difference between induction and late intensification. Am J Pediatr Hematol Oncol 1992;14(39:192-196.

[16] Heidemann PH, Stubbe P, Beck W. Transient secondary hypothyroidism and thyroxine binding globulin deficiency in leukemic children during polychemotherapy: an effect of L-asparaginase. Eur J Pediatr 1981;136(3):291-295.

[17] Massart C, Le Tellier C, Lucas C, Gibassier J, Leclech G, Nicol M. Effects of cisplatin on human thyrocytes in monolayer or follicle culture. J Mol Endocrinol 1992;8(3):243-248.

[18] Daffara F, De Francia S, Reimondo G, Zaggia B, Aroasio E, Porpiglia F, Volante M, Termine A, Di Carlo F, Dogliotti L, Angeli A, Berruti A, Terzolo M. Prospective evaluation of mitotane toxicity in adrenocortical cancer patients treated adjuvantly. Endocr Relat Cancer. 2008;15(4):1043-1053.

[19] Zatelli MC, Gentilin E, Daffara F, Tagliati F, Reimondo G, Carandina G, Ambrosio MR, Terzolo M, Degli Uberti EC. Therapeutic concentrations of mitotane [o,p'-DDD] inhibit thyrotroph cell viability and TSH expression and secretion in a mouse cell line model. Endocrinology 2010;151(6):2453-2461.

[20] Allolio B, Fassnacht M. Adrenocortical carcinoma: clinical update. Journal of Clinical Endocrinology and Metabolism 2006; 91(6):2027-37.

[21] Stuart NS, Woodroffe CM, Grundy R, Cullen MH. Long-term toxicity of chemotherapy for testicular cancer - the cost of cure. Br. J. Cancer 1990;61(3):479-484.

[22] Sutcliffe SB, Chapman R, Wrigley PF. Cyclical combination chemotherapy and thyroid function in patients with advanced Hodgkin's disease. Med. Pediatr Oncol 1981;9(5):439-448.

[23] Ogilvy-Stuart AL, Shalet SM, Gattamaneni HR. Thyroid function after treatment of brain tumors in children. J Pediatr 1991;119(5):733-737.

[24] Paulino AC. Hypothyroidism in children with medulloblastoma: a comparison of 3600 and 2340 cGy craniospinal radiotherapy. Int J Radiat Oncol Biol Phys 2002;53(3):543547.

[25] Jonasch E, Haluska FG. Interferon in oncological practice: review of interferon biology, clinical applications, and toxicities. Oncologist 2001;6(1):34-55.

[26] Fried MW, Shiffman ML, Reddy KR, Smith C, Marinos G, Goncales FL Jr., Haussinger D, Diago M, Carosi G, Dhumeaux D, Craxi A, Lin A, Hoffman J, Yu J. Peginterferon alfa-2a plus ribavirin for chronic hepatitis $C$ virus infection. $N$ Engl J Med 2002;347(13):975-982.

[27] Sroczynski G, Esteban E, Conrads-Frank A, Schwarzer R, Muhlberger N, Wright D, Zeuzem S, Siebert U. Long term effectiveness and cost-effectiveness of antiviral treatment in hepatitis C. J Viral Hepat 2010;17(1):34-50. 
[28] Tomer Y, Blackard JT, Akeno N. Interferon alpha treatment and thyroid dysfunction. Endocrinol Metab Clin North Am 2007;36(4):1051-1066.

[29] Tran HA, Malcolm Reeves GE, Gibson R, Attia JR. Development of thyroid diseases in the treatment of chronic hepatitis $C$ with alpha-interferon may be a good prognosticator in achieving a sustained virological response: a metaanalysis. J Gastroenterol Hepatol 2009;24(7):1163-1168.

[30] Kakizaki S, Takagi H, Murakami M, Takayama H, Mori M. HLA antigens in patients with interferon-alpha-induced autoimmune thyroid disorders in chronic hepatitis C. J Hepatol 1999;30(5):794-800.

[31] Dumoulin FL, Leifeld L, Sauerbruch T, Spengler U. Autoimmunity induced by interferon-alpha therapy for chronic viral hepatitis. Biomed Pharmacother 1999;53(56):242-254.

[32] Marcellin P, Pouteau M, Benhamou JP. Hepatitis C virus infection, alpha interferon therapy and thyroid dysfunction. J Hepatol 1995;22(3):364-369.

[33] Koh LK, Greenspan FS, Yeo PP. Interferon-alpha induced thyroid dysfunction: three clinical presentations and a review of the literature. Thyroid 1997;7(6):891-896.

[34] Okanoue T, Sakamoto S, Itoh Y, Minami M, Yasui K, Sakamoto M, Nishioji K, Katagishi T, Nakagawa Y, Tada H, Sawa Y, Mizuno M, Kagawa K, Kashima K.et al. Side effects of high-dose interferon therapy for chronic hepatitis C. J Hepatol 1996;25(3):283-291.

[35] Wong V, Fu AX, George J, Cheung NW. Thyrotoxicosis induced by alpha-interferon therapy in chronic viral hepatitis. Clin Endocrinol [Oxf]. 2002;56(6):793-798.

[36] Gisslinger H, Gilly B, Woloszczuk W, Mayr WR, Havelec L, Linkesch W, Weissel M. Thyroid autoimmunity and hypothyroidism during long-term treatment with recombinant interferon-alpha. Clin Exp Immunol 1992;90(3):363-367.

[37] Scalzo S, Gengaro A, Boccoli G, Masciulli R, Giannella G, Salvo G, Marolla P, Carlini P, Massimini G, Holdener EE, et al. Primary hypothyroidism associated with interleukin-2 and interferon alpha-2 therapy of melanoma and renal carcinoma. Eur J Cancer 1990;26(11-12):1152-1156.

[38] Fattovich G, Giustina G, Favarato S, Ruol A. A survey of adverse events in 11,241 patients with chronic viral hepatitis treated with alfa interferon. J Hepatol 1996;24(1):38-47.

[39] Tran HA, Jones TL, Ianna EA, Reeves GE. The natural history of interferon-alpha induced thyroiditis in chronic hepatitis $C$ patients: a long term study. Thyroid Res 2011;4(1):2. doi:10.1186/1756-6614-4-2

[40] Marazuela M, Garcia-Buey L, Gonzalez-Fernandez B, García-Monzón C, Arranz A, Borque MJ, Moreno-Otero R. Thyroid autoimmune disorders in patients with chronic hepatitis $\mathrm{C}$ before and during interferon-alpha therapy. Clin Endocrinol [Oxf] 1996;44(6):635-642.

[41] Deutsch M, Dourakis S, Manesis EK, Gioustozi A, Hess G, Horsch A, Hadziyannis S. Thyroid abnormalities in chronic viral hepatitis and their relationship to interferon alfa therapy. Hepatology 1997;26(1):206-210. 
[42] Roti E, Minelli R, Giuberti T, Marchelli S, Schianchi C, Gardini E, Salvi M, Fiaccadori F, Ugolotti G, Neri TM, Braverman LE. Multiple changes in thyroid function in patients with chronic active HCV hepatitis treated with recombinant interferon-alpha. Am J Med 1996;101(5):482-487.

[43] Corssmit EP, de Metz J, Sauerwein HP, Romijn JA. Biologic responses to IFN-alpha administration in humans. J Interferon Cytokine Res 2000;20(12):1039-1047.

[44] Yue SJ, Enomoto T, Matsumoto Y, Kawai K, Volpe R. Thyrocyte class I and class II upregulation is a secondary phenomenon and does not contribute to the pathogenesis of autoimmune thyroid disease. Thyroid 1998;8(9):755-763.

[45] Caraccio N, Giannini R, Cuccato S, Faviana P, Berti P, Galleri D, Dardano A, Basolo F, Ferrannini E, Monzani F. Type I interferons modulate the expression of thyroid peroxidase, sodium/iodide symporter, and thyroglobulin genes in primary human thyrocyte cultures. J Clin Endocrinol Metab. 2005;90(2):1156-1162.

[46] Barbesino G. Drugs affecting thyroid function. Thyroid 2010;20(7):763-70.

[47] Ward DL, Bing-You RG. Autoimmune thyroid dysfunction induced by interferon-alpha treatment for chronic hepatitis $\mathrm{C}$ : screening and monitoring recommendations. Endocr Pract 2001;7(1):52-58.

[48] Weijl NI, Van der Harst D, Brand A, Kooy Y, Van Luxemburg S, Schroder J, Lentjes E, Van Rood JJ, Cleton FJ, Osanto S. Hypothyroidism during immunotherapy with interleukin-2 is associated with antithyroid antibodies and response to treatment. J Clin Oncol 1993;11(7):1376-1383.

[49] Atkins MB, Mier JW, Parkinson DR, Gould JA, Berkman EM, Kaplan MM. Hypothyroidism after treatment with interleukin-2 and lymphokine-activated killer cells. N Engl J Med 1988;318(24):1557-1563.

[50] Fraenkel PG, Rutkove SB, Matheson JK, Fowkes M, Cannon ME, Patti ME, Atkins MB, Gollob JA. Induction of myasthenia gravis, myositis, and insulin-dependent diabetes mellitus by high-dose interleukin-2 in a patient with renal cell cancer. J Immunother 2002;25(4):373-378.

[51] Krouse RS, Royal RE, Heywood G, Weintraub BD, White DE, Steinberg SM, Rosenberg SA, Schwartzentruber DJ. Thyroid dysfunction in 281 patients with metastatic melanoma or renal carcinoma treated with interleukin-2 alone. J Immunother Emphasis Tumor Immunol 1995;18(4):272-278.

[52] Vialettes B, Guillerand MA, Viens P, Stoppa AM, Baume D, Sauvan R, Pasquier J, San Marco M, Olive D, Maraninchi D. Incidence rate and risk factors for thyroid dysfunction during recombinant interleukin-2 therapy in advanced malignancies. Acta Endocrinol [Copenh] 1993;129(1):31-38.

[53] Schwartzentruber DJ, White DE, Zweig MH, Weintraub BD, Rosenberg SA. Thyroid dysfunction associated with immunotherapy for patients with cancer. Cancer 1991;68(11):2384-2390.

[54] Jacobs EL, Clare-Salzler MJ, Chopra IJ, Figlin RA. Thyroid function abnormalities associated with the chronic outpatient administration of recombinant interleukin-2 and recombinant interferon-alpha. J Immunother 1991;10(6):448-455. 
[55] Vassilopoulou-Sellin R, Sella A, Dexeus FH, Theriault RL, Pololoff DA. Acute thyroid dysfunction [thyroiditis] after therapy with interleukin-2. Horm Metab Res 1992;24(9):434-438.

[56] Kragel AH, Travis WD, Feinberg L, Pittaluga S, Striker LM, Roberts WC, Lotze MT, Yang JJ, Rosenberg SA. Pathologic findings associated with interleukin-2-based immunotherapy for cancer: a postmortem study of 19 patients. Hum Pathol 1990;21(5):493-502.

[57] Pichert G, Jost LM, Zobeli L, Odermatt B, Pedia G, Stahel RA. Thyroiditis after treatment with interleukin-2 and interferon alpha-2a. Br J Cancer. 1990;62[1]:100-104.

[58] Gemlo BT, Palladino MA Jr., Jaffe HS, Espevik TP, Rayner AA. Circulating cytokines in patients with metastatic cancer treated with recombinant interleukin 2 and lymphokineactivated killer cells. Cancer Res 1988;48(20):5864-5867.

[59] Pang XP, Hershman JM, Chung M, Pekary AE. Characterization of tumor necrosis factor-alpha receptors in human and rat thyroid cells and regulation of the receptors by thyrotropin. Endocrinology 1989;125(4):1783-1788.

[60] Franzke A, Peest D, Probst-Kepper M, Buer J, Kirchner GI, Brabant G, Kirchner H, Ganser A, Atzpodien J. Autoimmunity resulting from cytokine treatment predicts longterm survival in patients with metastatic renal cell cancer. J Clin Oncol 1999;17(2):529_ 533.

[61] Krouse RS, Royal RE, Heywood G, Weintraub BD, White DE, Steinberg SM, Rosenberg SA, Schwartzentruber DJ. Thyroid dysfunction in 281 patients with metastatic melanoma or renal carcinoma treated with interleukin-2 alone. J Immunother Emphasis Tumor Immunol 1995;18(4):272-278.

[62] Phan GQ, Attia P, Steinberg SM, White DE, Rosenberg SA. Factors associated with response to high-dose interleukin-2 in patients with metastatic melanoma. J Clin Oncol 2001;19(15):3477-3482.

[63] Anderson KC. Lenalidomide and thalidomide: mechanisms of action-similarities and differences. Semin Hematol 2005;42(4;suppl 4):S3-S8.

[64] Kotla V, Goel S, Nischal S, Heuck C, Vivek K, Das B, Verma A. Mechanism of action of lenalidomide in hematological malignancies. J Hematol Oncol 2009;;2(8):36. doi:10.1186/1756-8722-2-36

[65] Choueiri TK, Dreicer R, Rini BI, Elson P, Garcia JA, Thakkar SG, Baz RC, Mekhail TM, Jinks HA, Bukowski RM Phase II study of lenalidomide in patients with metastatic renal cell carcinoma. Cancer 2006;107(11):2609-2616.

[66] Bartlett JB, Tozer A, Stirling D, Zeldis JB. Recent clinical studies of the immunomodulatory drug [IMiD] lenalidomide. Br J Cancer 2005;93(6):613-619.

[67] Ain KB, Lee C, Williams KD. Phase II trial of thalidomide for therapy of radioiodineunresponsive and rapidly progressive thyroid carcinomas. Thyroid 2007;17(7):663-670.

[68] de Savary N, Lee R, Vaidya B. Severe hypothyroidism after thalidomide treatment. J R Soc Med 2004;97(9):443. doi: 10.1258/jrsm.97.9.443 
[69] Badros AZ, Siegel E, Bodenner D, Zangari M, Zeldis J, Barlogie B, Tricot G. Hypothyroidism in patients with multiple myeloma following treatment with thalidomide. Am. J. Med 2002;112(5):412-413.

[70] Erdem F, Gundogdu M, Kiki I, Capoglu I. Autoimmune thyroiditis during thalidomide treatment. Am J Hematol 2006;81(2):152. DOI: 10.1002/ajh.20480

[71] Chowta MN, Chowta NK. Hypothyroidism caused by thalidomide. Indian J Med Sci 2006;60(10):424-426.

[72] Mateos MV. Management of treatment-related adverse events in patients with multiple myeloma. Cancer Treat Rev 2010;36(suppl 2):S24-S32.

[73] Gay F, Hayman SR, Lacy MQ, Buadi F, Gertz MA, Kumar S, Dispenzieri A, Mikhael JR, Bergsagel PL, Dingli D, Reeder CB, Lust JA, Russell SJ, Roy V, Zeldenrust SR, Witzig TE, Fonseca R, Kyle RA, Greipp PR, Stewart AK, Rajkumar SV. Lenalidomide plus dexamethasone versus thalidomide plus dexamethasone in newly diagnosed multiple myeloma: a comparative analysis of 411 patients. Blood 2010;115(7):1343-1350.

[74] List A, Dewald G, Bennett J, Giagounidis A, Raza A, Feldman E, Powell B, Greenberg P, Thomas D, Stone R, Reeder C, Wride K, Patin J, Schmidt M, Zeldis J, Knight R Lenalidomide in the myelodysplastic syndrome with chromosome $5 q$ deletion. N Engl J Med 2006;355(14):1456-1465.

[75] Dispenzieri A, Lacy MQ, Zeldenrust SR, Hayman SR, Kumar SK, Geyer SM, Lust JA, Allred JB, Witzig TE, Rajkumar SV, Greipp PR, Russell SJ, Kabat B, Gertz MA. The activity of lenalidomide with or without dexamethasone in patients with primary systemic amyloidosis. Blood 2007;109(2):465-470.

[76] Figaro MK, Clayton W Jr, Usoh C, Brown K, Kassim A, Lakhani VT, Jagasia S. al. Thyroid abnormalities in patients treated with lenalidomide for hematological malignancies: results of a retrospective case review. Am J Hematol 2011;86(6):467-470.

[77] Somers GF. Pharmacological properties of thalidomide [alpha-phthalimido glutarimide], a new sedative hypnotic drug. Br J Pharmacol Chemother 1960;15(1):111116.

[78] Murdoch JM, Campbell GD. Antithyroid activity of N-phthalyl glutamic acid imide [K17]. Br Med J 1958;1(5062):84-85.

[79] Giagounidis A, Fenaux P, Mufti GJ, Muus P, Platzbecker U, Sanz G, Cripe L, Von Lilienfeld-Toal M, Wells RA. Practical recommendations on the use of lenalidomide in the management of myelodysplastic syndromes. Ann Hematol 2008;87(5):345-352.

[80] Ledford H. Melanoma drug wins US approval. Nature 2011;471(7340):561. doi:10.1038/471561a

[81] Ribas A, Camacho LH, Lopez-Berestein G, et al. Antitumor activity in melanoma and anti-self responses in a phase I trial with the anti-cytotoxic $\mathrm{T}$ lymphocyte-associated antigen 4 monoclonal antibody CP-675,206. J Clin Oncol 2005;23(35):8968-8977.

[82] Min L, Vaidya A, Becker C. Thyroid autoimmunity and ophthalmopathy related to melanoma biological therapy. Eur J Endocrinol 2011;164(2):303-307.

[83] Bashey A, Medina B, Corringham S, Pasek M, Carrier E, Vrooman L, Lowy I, Solomon SR, Morris LE, Holland HK, Mason JR, Alyea EP, Soiffer RJ, Ball ED. CTLA4 blockade 
with ipilimumab to treat relapse of malignancy after allogeneic hematopoietic cell transplantation. Blood 2009;113(7):1581-1588.

[84] Torino F, Barnabei A, De Vecchis L, Salvatori R, Corsello SM. Hypophysitis induced by monoclonal antibodies to cytotoxic $\mathrm{T}$ lymphocyte antigen 4: challenges from a new cause of a rare disease. Oncologist 2012;17(4):525-35.

[85] Dillard T, Yedinak CG, Alumkal J, Fleseriu M. Anti-CTLA-4 antibody therapy associated autoimmune hypophysitis: Serious immune related adverse events across a spectrum of cancer subtypes. Pituitary 2010;13(1):29 -38.

[86] Chistiakov DA, Turakulov RI. CTLA-4 and its role in autoimmune thyroid disease. J Mol Endocrinol. 2003;31(1): 21-36. doi: 10.1677/jme.0.0310021

[87] Ribas A, Hauschild A, Kefford R, Punt CJ, Haanen JB, Marmol M, et al. Phase III, openlabel, randomized, comparative study of tremelimumab [CP-675,206] and chemotherapy [temozolomide [TMZ] or dacarbazine [DTIC]] in patients with advanced melanoma. J Clin Oncol 2008;26:9011.

http://meeting.ascopubs.org/cgi/content/abstract/26/15_suppl/LBA9011.

[88] Kirkwood JM, Lorigan P, Hersey P, Hauschild A, Robert C, McDermott D, Marshall MA, Gomez-Navarro J, Liang JQ, Bulanhagui CA. Phase II trial of tremelimumab [CP$675,206]$ in patients with advanced refractory or relapsed melanoma. Clin Cancer Res 2010;16(3):1042-1048.

[89] Hodi FS, O’Day SJ, McDermott DF, Weber RW, Sosman JA, Haanen JB, Gonzalez R, Robert C, Schadendorf D, Hassel JC, Akerley W, van den Eertwegh AJ, Lutzky J, Lorigan P, Vaubel JM, Linette GP, Hogg D, Ottensmeier CH, Lebbe C, Peschel C, Quirt I, Clark JI, Wolchok JD, Weber JS, Tian J, Yellin MJ, Nichol GM, Hoos A \& Urba WJ. Improved survival with ipilimumab in patients with metastatic melanoma. N Engl J Med 2010;363(8):711-723. doi:10.1056/NEJMoa1003466

[90] Weber J, Thompson JA, Hamid O, Minor D, Amin A, Ron I, Ridolfi R, Assi H, Maraveyas A, Berman D, Siegel J, O'Day SJ. A randomized, double-blind, placebocontrolled, phase II study comparing the tolerability and efficacy of ipilimumab administered with or without prophylactic budesonide in patients with unresectable stage III or IV melanoma. Clin Cancer Res 2009;15(17):5591-5598.

[91] Hodi FS, Friedlander PA, Atkins MB et al. A phase I trial of ipilimumab plus bevacizumab in patients with unresectable stage III or stage IV melanoma. J Clin Oncol 2011;29(15 suppl):8511.

[92] Maker AV, Phan GQ, Attia P, Yang JC, Sherry RM, Topalian SL, Kammula US, Royal RE, Haworth LR, Levy C, Kleiner D, Mavroukakis SA, Yellin M, Rosenberg SA. Tumor regression and autoimmunity in patients treated with cytotoxic $\mathrm{T}$ lymphocyteassociated antigen 4 blockade and interleukin 2: a phase I/II study. Ann Surg Oncol. 2005;12(12):1005-1016.

[93] Di Giacomo AM, Biagioli M, Maio M. The emerging toxicity profiles of anti-CTLA-4 antibodies across clinical indications. Semin Oncol 2010;37(5):499-507.

[94] Borodic G, Hinkle DM, Cia Y. Drug-induced graves disease from ctla-4 receptor suppression. Ophthal Plast Reconstr Surg. 2011; 27(4):e87-88. 
[95] Fabbro D, Cowan-Jacob SW, Möbitz H, Martiny-Baron G. Targeting cancer with smallmolecular-weight kinase inhibitors. Methods Mol Biol 2012;795:1-34.

[96] Lodish MB, Stratakis CA. Endocrine side effects of broad-acting kinase inhibitors. Endocr Relat Cancer. 2010;17(3):R233-44. doi: 10.1677/ERC-10-0082

[97] Brown RL. Tyrosine kinase inhibitor-induced hypothyroidism: incidence, etiology, and management. Targ Oncol (2011) 6:217-226 DOI 10.1007/s11523-011-0197-2

[98] de Groot JW, Zonnenberg BA, Plukker JT, van Der Graaf WT, Links TP. Imatinib induces hypothyroidism in patients receiving levothyroxine. Clin Pharmacol Ther 2005;78(4):433-438.

[99] Kundra P, Burman KD. The effect of medications on thyroid function tests. Med Clin North Am 2012;96(2):283-95.

[100] Gupta-Abramson V, Troxel AB, Nellore A, Puttaswamy K, Redlinger M, Ransone K, Mandel SJ, Flaherty KT, Loevner LA, O'Dwyer PJ, Brose MS. Phase II trial of sorafenib in advanced thyroid cancer. J Clin Oncol 2008;26(29):4714-4719.

[101] Schlumberger MJ, Elisei R, Bastholt L, Wirth LJ, Martins RG, Locati LD, Jarzab B, Pacini F, Daumerie C, Droz JP, Eschenberg MJ, Sun YN, Juan T, Stepan DE, Sherman SI. Phase II study of safety and efficacy of motesanib in patients with progressive or symptomatic, advanced or metastatic medullary thyroid cancer. J Clin Oncol 2009;27(23):3794-3801.

[102] Sherman SI, Wirth LJ, Droz JP, Hofmann M, Bastholt L, Martins RG, Licitra L, Eschenberg MJ, Sun YN, Juan T, Stepan DE, Schlumberger MJ. Motesanib diphosphate in progressive differentiated thyroid cancer. N Engl J Med 2008;359(1):31-42.

[103] Curran PG, DeGroot LJ. The effect of hepatic enzyme-inducing drugs on thyroid hormones and the thyroid gland. Endocr Rev 1991;12(2):135-150.

[104] Schröder-van der Elst JP, van der Heide D, DiStefano JJ 3rd, van der Bent C, Kaptein E, Visser TJ. Effects of 5, 5'-diphenylhydantoin on the metabolic pathway of thyroid hormone in rats. Eur. J. Endocrinol 1997;136(3):324-329.

[105] De Luca F, Arrigo T, Pandullo E, Siracusano MF, Benvenga S, Trimarchi F. Changes in thyroid function tests induced by 2 month carbamazepine treatment in L-thyroxinesubstituted hypothyroid children. Eur J Pediatr 1986;145(1-2):77-79.

[106] Takasu N, Takara M, Komiya I. Rifampin induced hypothyroidism in patients with Hashimoto's thyroiditis. N Engl J Med 2005;352(5):518-519.

[107] Grossmann M, Premaratne E, Desai J, Davis ID. Thyrotoxicosis during sunitinib treatment for renal cell carcinoma. Clin Endocrinol [Oxf] 2008;69(4):669-672.

[108] Faris JE, Moore AF, Daniels GH. Sunitinib [sutent]- induced thyrotoxicosis due to destructive thyroiditis: a case report. Thyroid 2007;17(11):1147-1149.

[109] Wong E, Rosen LS, Mulay M, Vanvugt A, Dinolfo M, Tomoda C, Sugawara M, Hershman JM. Sunitinib induces hypothyroidism in advanced cancer patients and may inhibit thyroid peroxidase activity. Thyroid 2007;17(4):351-355.

[110] Mannavola D, Coco P, Vannucchi G, Coco P, Vannucchi G, Bertuelli R, Carletto M, Casali PG, Beck-Peccoz P, Fugazzola L. A novel tyrosine-kinase selective inhibitor, 
sunitinib, induces transient hypothyroidism by blocking iodine uptake. J Clin Endocrinol Metab 2007;92(9):3531-3534.

[111] Rini BI, Tamaskar I, Shaheen P, Salas R, Garcia J, Wood L, Reddy S, Dreicer R, Bukowski RM. Hypothyroidism in patients with metastatic renal cell carcinoma treated with sunitinib. J Natl Cancer Inst 2007;99(1):81-83.

[112] Salem AK, Fenton MS, Marion KM, Hershman JM. Effect of sunitinib on growth and function of FRTL-5 thyroid cells. Thyroid 2008;18(6):631-635.

[113] Alexandrescu DT, Popoveniuc G, Farzanmehr H, Dasanu CA, Dawson N, Wartofsky L. et al. Sunitinib-associated lymphocytic thyroiditis without circulating antithyroid antibodies. Thyroid 2008;18(7):809-812.

[114] Tamaskar I, Bukowski R, Elson P, Ioachimescu AG, Wood L, Dreicer R, Mekhail T, Garcia J, Rini BI. Thyroid function test abnormalities in patients with metastatic renal cell carcinoma treated with sorafenib. Ann Oncol 2008;19(2):265-268.

[115] Kamba T, Tam BY, Hashizume H, Haskell A, Sennino B, Mancuso MR, Norberg SM, O'Brien SM, Davis RB, Gowen LC, Anderson KD, Thurston G, Joho S, Springer ML, Kuo CJ, McDonald DM. VEGF-dependent plasticity of fenestrated capillaries in the normal adult microvasculature. Am J Physiol Heart Circ Physiol 2006;290(2):H560-H576.

[116] Makita N, Miyakawa M, Fujita T, Iiri T. Sunitinib induces hypothyroidism with a markedly reduced vascularity. Thyroid 2010;20(3):323-326.

[117] Rogiers A, Wolter P, Op de Beeck K, Thijs M, Decallonne B, Schöffski P. Shrinkage of thyroid volume in sunitinib-treated patients with renal-cell carcinoma: a potential marker of irreversible thyroid dysfunction? Thyroid 2010;20(3):317-322.

[118] Hershman JM, Liwanpo L. How does sunitinib cause hypothyroidism? Thyroid 2010;20(3):243-244.

[119] Willett CG, Boucher Y, di Tomaso E, Duda DG, Munn LL, Tong RT, Chung DC, Sahani DV, Kalva SP, Kozin SV, Mino M, Cohen KS, Scadden DT, Hartford AC, Fischman AJ, Clark JW, Ryan DP, Zhu AX, Blaszkowsky LS, Chen HX, Shellito PC, Lauwers GY, Jain RK. Direct evidence that the VEGF specific antibody bevacizumab has antivascular effects in human rectal cancer. Nat Med 2004;10(2):145-147.

[120] Willett CG, Boucher Y, Duda DG, di Tomaso E, Munn LL, Tong RT, Kozin SV, Petit L, Jain RK, Chung DC, Sahani DV, Kalva SP, Cohen KS, Scadden DT, Fischman AJ, Clark JW, Ryan DP, Zhu AX, Blaszkowsky LS, Shellito PC, Mino-Kenudson M, Lauwers GY. Surrogate markers for antiangiogenic therapy and dose-limiting toxicities for bevacizumab with radiation and chemotherapy: continued experience of a phase i trial in rectal cancer patients. J Clin Oncol 2005;23(31):8136-8139.

[121] Dora JM, Leie MA, Netto B, Fogliatto LM, Silla L, Torres F, Maia AL. Lack of imatinibinduced thyroid dysfunction in a cohort of non-thyroidectomized patients. Eur J Endocrinol 2008;158(5):771-772.

[122] de Groot JW, Links TP, van der Graaf WT. Tyrosine kinase inhibitors causing hypothyroidism in a patient on levothyroxine. Ann Oncol 2006;17(11):1719-1720. doi: 10.1093/annonc/mdl112. 
[123] Desai J, Yassa L, Marqusee E, George S, Frates MC, Chen MH, Morgan JA, Dychter SS, Larsen PR, Demetri GD, Alexander EK. Hypothyroidism after sunitinib treatment for patients with gastrointestinal stromal tumors. Ann Intern Med 2006;145(9):660-664.

[124] Feldman DR, Martorella AJ, Robbins RJ, Motzer RJ. Re: hypothyroidism in patients with metastatic renal cell carcinoma treated with sunitinib. J Natl Cancer Inst 2007;99(12):974-975.

[125] Wolter P, Stefan C, Decallonne B, Dumez H, Bex M, Carmeliet P, Schoffski P. The clinical implications of sunitinib-induced hypothyroidism: a prospective evaluation. $\mathrm{Br}$ J Cancer 2008;99(3):448-454. doi:10.1038/sj.bjc.6604497

[126] Schmidinger M, Vogl UM, Bojic M, Lamm W, Heinzl H, Haitel A, Clodi M, Kramer G, Zielinski CC. Hypothyroidism in patients with renal cell carcinoma: blessing or curse? Cancer 2011;117(3)::534-544. doi: 10.1002/cncr.25422.

[127] Riesenbeck LM, Bierer S, HoVmeister I, Köpke T, Papavassilis P, Hertle L, Thielen B, Herrmann E. Hypothyroidism correlates with a better prognosis in metastatic renal cancer patients treated with sorafenib or sunitinib. World J Urol 2011;29(6):807-813. DOI 10.1007/s00345-010-0627-2

[128] Clement P WP, Stefan C, Decallonne B, Dumez H, Wildiers H, Schöffski P. J Clin Oncol 2008;26(20 suppl): abstr 16145.

[129] Miyake H, Kurahashi T, Yamanaka K, Kondo Y, Muramaki M, Takenaka A, Inoue TA, Fujisawa M. Abnormalities of thyroid function in Japanese patients with metastatic renal cell carcinoma treated with sorafenib: a prospective evaluation. Urol Oncol 2010;28(5):515-519.

[130] Iavarone M, Perrino M, Viganò M, Beck-Peccoz P, Fugazzola L. Sorafenib-induced destructive thyroiditis. Thyroid 2010;20(9):1043-1044.

[131] van Doorn L, Eskens FA, Visser TJ, van der Lugt A, Mathijssen RH, Peeters RP. Sorafenib induced thyroiditis in two patients with hepatocellular carcinoma. Thyroid 2011;21(2):197-202.

[132] Abdulrahman RM, Verloop H, Hoftijzer H, Verburg E, Hovens GC, Corssmit EP, Reiners C, Gelderblom H, Pereira AM, Kapiteijn E, Romijn JA, Visser TJ, Smit JW. Sorafenib-induced hypothyroidism is associated with increased type 3 deiodination. J Clin Endocrinol Metab 2010;95(8):3758-62.

[133] Benjamin RS, Schöffski P, Hartmann JT, Van Oosterom A, Bui BN, Duyster J, Schuetze S, Blay JY, Reichardt P, Rosen LS, Skubitz K, McCoy S, Sun YN, Stepan DE, Baker L. Efficacy and safety of motesanib, an oral inhibitor of VEGF, PDGF, and Kit receptors, in patients with imatinib-resistant gastrointestinal stromal tumors. Cancer Chemother Pharmacol 2011;68(1):69-77.

[134] Brassard M, Rondeau G. Role of vandetanib in the management of medullary thyroid cancer. Biologics 2012;6:59-66. doi: 10.2147/BTT.S24220

[135] Robinson BG, Paz-Ares L, Krebs A, Vasselli J, Haddad R. Vandetanib [100 mg] in patients with locally advanced or metastatic hereditary medullary thyroid cancer. J Clin Endocrinol Metab 2010;95(6):2664-2671. doi: 10.1210/jc.2009-2461 
[136] Brassard M, Neraud B, Trabado S, Salenave S, Brailly-Tabard S, Borget I, Baudin E, Leboulleux S, Chanson P, Schlumberger M, Young J. Endocrine effects of the tyrosine kinase inhibitor vandetanib in patients treated for thyroid cancer. J Clin Endocrinol Metab 2011;96(9):2741-2749.

[137] Kelly RJ, Rixe O. Axitinib [AG-013736]. Recent Results Cancer Res 2010;184:33-44

[138] Fujiwara Y, Kiyota N, Chayahara N, Suzuki A, Umeyama Y, Mukohara T, Minami H. Management of axitinib [AG-013736]-induced fatigue and thyroid dysfunction, and predictive biomarkers of axitinib exposure: results from phase I studies in Japanese patients. Investig New Drugs. 2012;30(3):1055-64. doi:10.1007/ s10637-011-9637-1

[139] Rini BI, Wilding G, Hudes G, Stadler WM, Kim S, Tarazi J, Rosbrook B, Trask PC, Wood L, Dutcher JP. Phase II study of axitinib in sorafenib-refractory metastatic renal cell carcinoma. J Clin Oncol 2009;20(27):4462-4468.

[140] Baffert F, Le T, Sennino B, Thurston G, Kuo CJ, Hu-Lowe D, McDonald DM. Cellular changes in normal blood capillaries undergoing regression after inhibition of VEGF signaling. Am J Physiol Heart Circ Physiol 2006;290(2):H547-H559. doi: 10.1152/ ajpheart.00616.2005

[141] Weisberg E, Catley L, Wright RD, Moreno D, Banerji L, Ray A, Manley PW, Mestan J, Fabbro D, Jiang J, Hall-Meyers E, Callahan L, DellaGatta JL, Kung AL, Griffin JD. Beneficial effects of combining nilotinib and imatinib in preclinical models of BCRABL+ leukemias. Blood 2007;109(5):2112-2120. doi: 10.1182/blood-2006-06-026377

[142] Manley PW, Drueckes P, Fendrich G, Furet P, Liebetanz J, Martiny-Baron G, Mestan J, Trappe J, Wartmann M, Fabbro D. Extended kinase profile and properties of the protein kinase inhibitor nilotinib. Biochim Biophys Acta 2010;1804(3):445-453.

[143] Kim TD, Schwarz M, Nogai H, Grille P, Westermann J, Plockinger U, Braun D, Schweizer U, Arnold R, Dorken B, le Coutre P. Thyroid dysfunction caused by secondgeneration tyrosine kinase inhibitors in Philadelphia chromosomepositive chronic myeloid leukemia. Thyroid 2011; 20(11):1209-1214.

[144] Yoshizato T, Nannya Y, Yoshiki Y, Nakamura F, Imai Y, Ichikawa M, Kurokawa M. Nilotinib-induced hypothyroidism in a patient with chronic myeloid leukemia. Int J Hematol 2011;93(3):400-402.

[145] Ohanian M, Cortes J, Kantarjian H, Jabbour E. Tyrosine kinase inhibitors in acute and chronic leukemias. Expert Opin Pharmacother 2012;13(7):927-938.

[146] Wolter P, McCann L, Sternberg CN, Hutson TE, Mehmud F, Pandite LN, Schoffski P. Incidence of thyroid dysfunction in renal cell carcinoma [RCC] patients treated with pazopanib in prospective clinical trials. J Clin Oncol 2011; (29 suppl); abstr 4633.

[147] Goss GD, Arnold A, Shepherd FA, Dediu M, Ciuleanu TE, Fenton D, Zukin M, Walde D, Laberge F, Vincent MD, Ellis PM, Laurie SA, Ding K, Frymire E, Gauthier I, Leighl NB, Ho C, Noble J, Lee CW, Seymour L. Randomized, double-blind trial of carboplatin and paclitaxel with either daily oral cediranib or placebo in advanced non-small-cell lung cancer: NCIC clinical trials group BR24 study. J Clin Oncol 2010;28(1):49-55.

[148] Matulonis UA, Berlin S, Ivy P, Tyburski K, Krasner C, Zarwan C, Berkenblit A, Campos S, Horowitz N, Cannistra SA, Lee H, Lee J, Roche M, Hill M, Whalen C, 
Sullivan L, Tran C, Humphreys BD, Penson RT. Cediranib, an oral inhibitor of vascular endothelial growth factor receptor kinases, is an active drug in recurrent epithelial ovarian, fallopian tube, and peritoneal cancer. J Clin Oncol 2009;20(33):5601-5606.

[149] Sharma V, Hays WR, Wood WM, et al. Effects of rexinoids on thyrotrope function and the hypothalamic-pituitary-thyroid axis. Endocrinology 2006;147(3):1438-1451.

[150] Smith JW, Stokkel MP, Pereira AM, Romijn JA, Visser TJ. Bexarotene-induced hypothyroidism: bexarotene stimulates the peripheral metabolism of thyroid hormones. J Clin Endocrinol Metab 2007;92(7):2496-2499.

[151] O'Connor P, Feely J. Clinical pharmacokinetics and endocrine disorders. Therapeutic implications. Clin Pharmacokinet 1987;13(6):345-364.

[152] Chen SY, Kao PC, Lin ZZ, Chiang WC, Fang CC. Sunitinib-induced myxedema coma. Am J Emerg Med 2009;27(3):370.e1-370.e3.

[153] Collinson F, Vasudev N, Berkin L, Khan MM, Selby PJ, Brown JE. Sunitinib-induced severe hypothyroidism with cardiac compromise Med Oncol 2010;28(Suppl 1):S699-701. doi:10.1007/s12032-010-9757-z.

[154] Di Lorenzo G, Autorino R, Bruni G, Cartenì G, Ricevuto E, Tudini M, Ficorella C, Romano C, Aieta M, Giordano A, Giuliano M, Gonnella A, De Nunzio C, Rizzo M, Montesarchio V, Ewer M, De Placido S. Cardiovascular toxicity following sunitinib therapy in metastatic renal cell carcinoma: a multicenter analysis. Ann Oncol 2009;20(9):1535-1542.

[155] Cristofanilli M, Yamamura Y, Kau SW, Bevers T, Strom S, Patangan M, Hsu L, Krishnamurthy S, Theriault RL, Hortobagyi GN. Thyroid hormone and breast carcinoma. Primary hypothyroidism is associated with a reduced incidence of primary breast carcinoma. Cancer 2005;103(6):1122-1128.

[156] Nelson M, Hercbergs A, Rybicki L, Strome M. Association between development of hypothyroidism and improved survival in patients with head and neck cancer. Arch Otolaryngol Head Neck Surg 2006;132(10):1041-1046.

[157] Hercbergs AA, Goyal LK, Suh JH, Lee S, Reddy CA, Cohen BH, Stevens GH, Reddy SK, Peereboom DM, Elson PJ, Gupta MK, Barnett GH. Propylthiouracil-induced chemical hypothyroidism with high-dose tamoxifen prolongs survival in recurrent high grade glioma: a phase I/II study. Anticancer Res 2003;23(1B):617-626.

[158] Wolter P, Stefan C, Decallonne B, et al. Evaluation of thyroid dysfunction as a candidate surrogate marker for efficacy of sunitinib in patients [pts] with advanced renal cell carcinoma [RCC]. J Clin Oncol 2008;26(15S): abstract 5126.

[159] Yang JC, Hughes M, Kammula U, Royal R, Sherry RM, Topalian SL, Suri KB, Levy C, Allen T, Mavroukakis S, Lowy I, White DE, Rosenberg SA. Ipilimumab [anti-CTLA4 antibody] causes regression of metastatic renal cell cancer associated with enteritis and hypophysitis. J Immunother 2007;30(8):825-830.

[160] Eisen T, Sternberg CN, Robert C, Mulders P, Pyle L, Zbinden S, Izzedine H, Escudier B. Targeted therapies for renal cell carcinoma: review of adverse event management strategies. J Natl Cancer Inst 2012;104(2):93-113. 
[161] Baskin HJ, Cobin RH, Duick DS, Gharib H, Guttler RB, Kaplan MM, Segal RL. American Association of Clinical Endocrinologists medical guidelines for clinical practice for the evaluation and treatment of hyperthyroidism and hypothyroidism. Endocr Pract 2002;8(6):457-469.

[162] Surks MI, Ortiz E, Daniels GH, Sawin CT, Col NF, Cobin RH, Franklyn JA, Hershman JM, Burman KD, Denke MA, Gorman C, Cooper RS, Weissman NJ. Subclinical thyroid disease: scientific review and guidelines for diagnosis and management. JAMA 2004;291(2):228-238. doi: 10.1001/jama.291.2.228

[163] Garfield DH, Hercbergs A, Davis PJ. Re: Hypothyroidism in patients with metastatic renal cell carcinoma treated with sunitinib. J Natl Cancer Inst 2007;99(12):975-976.

[164] Davis PJ, Davis FB, Lin HY, Bergh JJ, Mousa S, Hercbergs A, Fenstermaker RA, Ciesielski MJ. Cell surface receptor for thyroid hormone and tumor cell proliferation. Exp Rev Endocrinol Metabol 2007;1(6):753-761. DOI 10.1586/17446651.1.6.753

[165] Torino F, Corsello SM, Longo R, Barnabei A, Gasparini G. Is hypothyroidism a clinically relevant toxicity of tyrosine kinase inhibitors? Thyroid 2009;19(5):539-40. 